\title{
Calling Acute Bronchitis a Chest Cold May Improve Patient Satisfaction with Appropriate Antibiotic Use
}

\author{
T. Grant Phillips, MD, and John Hickner, MD, MS
}

Background: Overuse of antibiotics for acute respiratory infections is an important public health problem and occurs in part because of pressure on physicians by patients to prescribe them. We hypothesized that if acute respiratory infections are called "chest colds" or "viral infections" rather than "bronchitis," patients will be satisfied with the diagnosis and more satisfied with not receiving antibiotics.

Methods: Family medicine patients were presented with a written scenario describing a typical acute respiratory infection where they were given one of 3 different diagnostic labels: chest cold, viral upper respiratory infection, and bronchitis, followed by a treatment plan that excluded antibiotic treatment. Data was analyzed for satisfaction with the diagnosis and treatment plan based on the diagnostic label. A total of 459 questionnaires were collected.

Results: Satisfaction $(70 \%, 63 \%$, and $68 \%)$ and dissatisfaction $(11 \% 13 \%$, and $13 \%)$ with the diagnostic labels of cold, viral upper respiratory infection, and bronchitis, respectively, showed no difference $\left(\chi^{2}=0.368, P=.832\right)$. However, more patients were dissatisfied with not receiving an antibiotic when the diagnosis label was bronchitis. A total of $26 \%$ of those that were told they had bronchitis were dissatisfied with their treatment, compared with $13 \%$ and $17 \%$ for colds and viral illness, respectively, $\left(\chi^{2}=9.380, P=.009\right)$. Binary logistic regression showed no difference in satisfaction with diagnosis for educational attainment, age, and sex $($ odds ratio $(O R)=1.09,1.00,0.98$, respectively $)$, or for satisfaction with treatment $(\mathrm{OR}=1.1,1.02,1.00$, respectively $)$.

Conclusions: Provider use of benign-sounding labels such as chest cold when a patient presents for care for an acute respiratory infection may not affect patient satisfaction but may improve satisfaction with not being prescribed an antibiotic. (J Am Board Fam Pract 2005;18:459-63.)

Antibiotic resistance is an important public health problem, ${ }^{1,2}$ and inappropriate antibiotic prescribing by primary care practitioners for acute respiratory infections (ARI) is a contributing factor. ${ }^{3}$ No universal definition for ARI exists, although the term ARI is generally applied to a self-limited upper respiratory illness associated with some or all the following symptoms: cough, nasal congestion, runny nose, sinus pressure, fever, and sore throat. Depending on the predominate symptom, the illness may be called pharyngitis, upper respiratory infection, sinusitis, or acute bronchitis when the predominant symptom is cough. Despite consistent

Submitted 24 March 2005; revised 15 June 2005; accepted 26 July 2005.

From the Washington Family Practice Residency Program, Washington, PA 15301 (TGP); and Department of Family Medicine, The University of Chicago Pritzker School of Medicine, Chicago, IL 60637 (JH)

Funding: This study was funded by a research stimulation grant G0405RS from the AAFP Foundation.

Conflict of interest: none declared.

Corresponding author: T. Grant Phillips, MD, Washington Family Practice Residency Program, 95 Leonard Avenue, Washington, PA 15301 (tphillips@washingtonhospital.org). evidence from randomized trials that antibiotics are ineffective for most patients with ARIs, there is still considerable antibiotic overprescribing. Combined National Ambulatory Medical Care Survey data from 2001 and 2002 show that $48.3 \%$ of patients presenting for office care to family physicians and general internists who have a diagnosis of upper respiratory infection received a prescription for an antibiotic, as did $58.7 \%$ of those diagnosed with acute bronchitis. (Special analysis performed for this study by David Woodwell from the National Center for Health Statistics, March 2005.). The antibiotic-prescribing rate for acute bronchitis has not changed from 1999 when $59 \%$ of adults in community-based outpatient practices received an antibiotic prescription for acute bronchitis. ${ }^{4}$

Patient pressure plays a role in antibiotic overprescribing. ${ }^{5}$ Bauchner et $\mathrm{al}^{6}$ found that $54 \%$ of pediatricians felt parental pressure to prescribe antibiotics inappropriately. This pressure is often effective. Hamm et $\mathrm{al}^{7}$ found that when patients wanted antibiotics for acute respiratory infections, physicians prescribed them $77 \%$ of the time, but 
they prescribed them only $29 \%$ of the time when the patient did not ask for an antibiotic.

One possible way to decrease antibiotic prescribing for acute bronchitis would be to reduce patient pressure on physicians to prescribe them. This might be accomplished through patient education, but it is also possible that "reframing" the seriousness of the condition by using a more benign label such as "chest cold" rather than "acute bronchitis" will reduce patient expectations for an antibiotic.

We hypothesized that when presented with a scenario describing acute bronchitis, patients will be as satisfied with receiving the diagnosis of chest cold as they would be if they had received a diagnosis of either bronchitis or viral upper respiratory infection. Furthermore, we hypothesized that patients will be more satisfied with not receiving a prescription for an antibiotic if they are told they have a chest cold rather than bronchitis.

\section{Methods}

We developed a written scenario representing a typical case of acute bronchitis. Six family practitioners or pediatricians reviewed the scenario and agreed that it represented a typical acute respiratory illness that might be called bronchitis but does not require antibiotic therapy.

The scenario reads:

Description of Visit: You have had a cough for 1 week that is not going away. You are bringing up phlegm that is a dark gray color. You had a fever at the beginning of the illness, but do not have one now. You do not have a runny nose or sore throat. The doctor examines your ears, nose, throat, and listens to your chest with a stethoscope. You came in because you wondered if an antibiotic would help you get better faster.

At the conclusion of the scenario, the following statement was made with 3 variations: The doctor tells you that you have (a chest cold, a viral upper respiratory infection, or bronchitis). He says that you will get over it just as fast without an antibiotic and does not prescribe an antibiotic for you.

The scenario was followed by 2 questions that were identical for all 3 illness labels: (1) How satisfied are you with the diagnosis of (condition)? (2) How satisfied are you with not receiving an antibi- otic prescription? Patients were asked about their level of satisfaction using a 5-point Likert scale ranging from very satisfied to very dissatisfied. $\mathrm{Pa}$ tients were also asked to provide their sex, age, and educational attainment on the form.

Equal numbers of surveys representing the 3 different labels were printed and shuffled repeatedly by 2 people to randomize the order of presentation to patients. The surveys were given to patients who presented to the office for routine appointments other than acute respiratory infections. Office staff asked patients to participate in the study and gave them questionnaires to complete in the waiting room. Completed questionnaires were returned to the receptionist. If a patient chose to return a blank questionnaire, this was returned to the pool and counted into the denominator for the response rate.

The questionnaire was distributed in 3 separate sites. Two offices were family practice residency clinics of the same residency in southwestern Pennsylvania, and the third was a private family practice in central Pennsylvania without an academic affiliation. The proportion of questionnaires distributed to each office was based on estimates of the fulltime physician equivalents at the offices. The community office has 3 physician FTEs and 80 questionnaires were distributed there. The family practice residency clinics had 13 physician FTEs and 362 questionnaires were distributed.

To detect an absolute difference in satisfaction of $15 \%$ with a 2 -tailed $\alpha$ of 0.05 and $\beta$ of $80 \%$, approximately 136 useable surveys were needed for each satisfaction group. For the analysis, we collapsed the patient satisfaction categories by grouping the 2 "satisfied" categories and the 2 "dissatisfied" categories. Those who responded "neither satisfied nor dissatisfied" were excluded from the analysis because they would not contribute to distinguishing satisfied from dissatisfied patients.

Differences in satisfaction rates were analyzed using a $\chi^{2}$ test. To check for differences in the distribution of the 3 questionnaire types by age, sex, and educational attainment, we used analysis of variance (ANOVA) for age and $\chi^{2}$ for sex and educational attainment. We used binary logistic regression to control for differences in age, sex, and educational attainment in the analyses of satisfaction with the diagnosis and satisfaction with the treatment. The data were analyzed using Minitab 14 statistical software (Minitab, State College, PA). 


\section{Results}

A total of 466 questionnaires was distributed. Four questionnaires were unaccounted for, and 3 were incomplete or unusable, leaving a total of 459 questionnaires available for analysis.

The average age of respondents was 43 . The educational attainment by category was: $12 \%$ never finished high school, 39\% high school graduate or GED, 27\% some college or associate degree, and $22 \%$ college degree or other advanced degree. Women represented $66 \%$ of respondents. There were no statistically significant differences in the ages $(F=0.19, P=.824)$ and educational levels $\left(\chi^{2}\right.$ $=10.312, P=.112)$ among the groups receiving the different diagnostic labels. More women than men answered the questionnaire in all groups, but there were no statistically significant sex differences by questionnaire type $(64 \%, 64 \%, 69 \%$ for colds, viral upper respiratory infection, and bronchitis, respectively; $\chi^{2}=0.977, P=.614$ ).

Table 1 shows the response to satisfaction with the diagnosis. Table 2 shows satisfaction with treatment. With the neutral group removed from analysis, satisfaction $(70 \%, 63 \%, 68 \%)$ and dissatisfaction $(11 \% 13 \%, 13 \%)$ with the diagnoses of cold, viral upper respiratory infection, and bronchitis, respectively, did not differ significantly by diagnostic label $\left(\chi^{2}=0.368, P=.832\right)$. However, more patients were dissatisfied with not receiving an antibiotic when the diagnosis label was bronchitis. A total of $26 \%$ of those that were told they had bronchitis were dissatisfied with their treatment, compared with $13 \%$ and $17 \%$ for colds and viral illness, respectively $\left(\chi^{2}=9.380, P=.009\right)$. Table 3 shows the results of binary logistic regression analyses for satisfaction with diagnosis and treatment, adjusting for age, sex, and education. Satisfaction with the diagnosis and treatment was not affected by age, sex, and education of the participants.

\section{Discussion}

Physicians may use terms like viral syndrome and chest cold with the idea that this term represents a less serious illness that does not require antibiotic treatment. The term bronchitis means acute or chronic inflammation of the bronchial tubes, ${ }^{8}$ without implying an etiology, but for many patients and physicians, this term has evolved into a description of a more serious acute respiratory illness that is perceived as requiring antibiotic treatment. ${ }^{9}$

In this study, we presented patients with a hypothetical scenario depicting an acute cough illness, and we gave that same illness 3 different diagnostic labels: chest cold, viral upper respiratory infection, and bronchitis. The respondents, adult patients in the office for nonrespiratory illness complaints, were equally satisfied or dissatisfied with all 3 diagnostic labels. Because the patient in the scenario had been moderately ill for a week, it would have been reasonable to expect that more patients would have been dissatisfied with being told they had a chest cold or viral upper respiratory illness, but this was not the case. This supports the notion that given a scenario that represents a typical case of what might be labeled acute bronchitis, the diagnosis appears to make little difference to patients. Yet by calling the condition bronchitis, more patients were dissatisfied with not receiving an antibiotic compared with calling the illness a chest cold or viral upper respiratory infection. Our hypothesis that the label a clinician uses for an acute cough illness can influence expectations for an antibiotic is supported by this pilot study.

We found only one previous study that describes how physician labeling of acute respiratory infections might affect patients' expectations and subsequent antibiotic prescribing. Gonzales ${ }^{10}$ found that patients believed that colds and bronchitis are different illnesses and that bronchitis is more likely to be perceived as an infection requiring antibiotics.

Table 1. Patient Satisfaction with Different Diagnostic Labels Used in a Scenario of Acute Cough Illness*

\begin{tabular}{|c|c|c|c|c|}
\hline Diagnostic Label & $\begin{array}{c}\text { Satisfied or Very } \\
\text { Satisfied } \\
\text { N }(\%)\end{array}$ & $\begin{array}{c}\text { Neither Satisfied } \\
\text { nor Dissatisfied } \\
\text { N }(\%)\end{array}$ & $\begin{array}{c}\text { Dissatisfied or } \\
\text { Very Dissatisfied } \\
\mathrm{N}(\%)\end{array}$ & $\begin{array}{l}\text { Total } \\
\text { N (\%) }\end{array}$ \\
\hline Viral upper respiratory infection & $106(70)$ & $28(19)$ & $17(11)$ & $151(100)$ \\
\hline Cold & $96(63)$ & $37(24)$ & $19(13)$ & $152(100)$ \\
\hline Bronchitis & $106(68)$ & $30(19)$ & $20(13)$ & $\begin{array}{l}156(100) \\
459\end{array}$ \\
\hline
\end{tabular}

* The "neither satisfied nor dissatisfied" response group was not included in the statistical testing. $\chi^{2}=0.368 P=.832$. 
Table 2. Patient Satisfaction with Not Receiving an Antibiotic When Presented with Different Diagnostic Labels to Describe a Scenario of Acute Cough Illness*

\begin{tabular}{|c|c|c|c|c|}
\hline Diagnostic Label & $\begin{array}{c}\text { Satisfied or Very } \\
\text { Satisfied } \\
\text { N (\%) }\end{array}$ & $\begin{array}{c}\text { Neither Satisfied } \\
\text { nor Dissatisfied } \\
\text { N (\%) }\end{array}$ & $\begin{array}{c}\text { Dissatisfied or } \\
\text { Very Dissatisfied } \\
\text { N (\%) }\end{array}$ & $\begin{array}{c}\text { Total } \\
\text { N (\%) }\end{array}$ \\
\hline Viral upper respiratory infection & $87(58)$ & $44(29)$ & $20(13)$ & $151(100)$ \\
\hline Cold & $76(50)$ & $50(33)$ & $26(17)$ & $152(100)$ \\
\hline Bronchitis & $70(45)$ & $45(29)$ & $41(26)$ & $\begin{array}{l}156(100) \\
459\end{array}$ \\
\hline
\end{tabular}

* The "neither satisfied nor dissatisfied" response group was not included in the statistical testing. $\chi^{2}=9.380, P=.009$.

In that study, $63 \%$ of the patients reported being always or nearly always treated with antibiotics when the diagnosis was bronchitis. Collett et $\mathrm{al}^{11}$ noted that $38 \%$ of patients thought an antibiotic would help the common cold, whereas 57\% thought an antibiotic would help bronchitis. Based on these studies, when physicians tell patients they have bronchitis, at least half of them believe they need an antibiotic. On the other hand, if clinicians used the label chest cold we suspect that fewer patients would expect an antibiotic. Our study results were consistent with this hypothesis.

This study has obvious limitations. It was conducted on a convenience sample of patients in only 3 offices in the northeastern United States. Furthermore, we presented a hypothetical scenario to patients who did not present for care of an acute respiratory infection. We do not know how these patients would have responded to the scenario had they had a respiratory infection at the time. More importantly, we do not know how patients with real acute respiratory infections would respond to these labels when presenting to their physicians for treatment. Based on the suggestive evidence from this study, we intend to conduct a randomized clinical trial to test our diagnostic labeling hypothesis in

Table 3. Logistic Regression Comparing Satisfaction with Diagnosis and Treatment Plans Based on Education, Age, and Sex

\begin{tabular}{lcc}
\hline & Adjusted OR & $95 \%$ CI \\
\hline Satisfaction with diagnosis & & \\
Education & 1.09 & $0.89-1.33$ \\
Age & 1.00 & $0.99-1.02$ \\
Sex & 0.98 & $0.65-1.48$ \\
Satisfaction with treatment & & \\
Education & 1.14 & $0.94-1.39$ \\
Age & 1.02 & $1.00-1.03$ \\
Sex & 1.00 & $0.68-1.49$ \\
\hline
\end{tabular}

patients presenting to their physicians with acute respiratory infections that physicians would ordinarily label acute bronchitis.

Until a randomized trial is conducted to test the hypothesis that diagnostic labels affect patient expectation for an antibiotic and satisfaction with treatment, it seems reasonable to label cough predominant acute respiratory illness (other than pneumonia) as a chest cold or acute respiratory infection and avoid terms like bronchitis. Our data suggest that patients will be just as satisfied with the diagnosis, and more importantly, will be satisfied with not receiving an antibiotic prescription. This simple intervention may make a difference and lead to decreased antibiotic prescribing.

We thank Stephen J. Pandolph, MD (State College, PA), for assisting in the data collection. TGP and JH contributed equally in study design, analysis, and preparation of the manuscript. TGP collected and analyzed the data.

\section{References}

1. Nyquist A, Gonzales R, Steiner JF, Sande MA. Antibiotic prescribing for children with upper respiratory tract infections and bronchitis. JAMA 1998;279: 875-7.

2. Albrich WC, Monnet DL, Harbarth S. Antibiotic selection pressure and resistance in Streptococcus pneumoniae and Streptococcus pyogenes. Emerg Infect Dis 2004;10:514-7.

3. Brown DW, Taylor R, Rogers A, Weiser R, Kelley M. Antibiotic prescriptions associated with outpatient visits for acute upper respiratory tract infections among adult Medicaid recipients in North Carolina. N C Med J 2003;64:148-56.

4. Steinman M, Gonzales R, Linder JA, Landefeld CS. Changing use of antibiotics in community-based outpatient practice, 1991-1999. Ann Intern Med 2003;138:525-33.

5. Scott JG, Cohen D, DiCicco-Bloom B, Orzano AJ, Jaen CR, Crabtree BF. Antibiotic use in acute respi- 
ratory infections and the ways patients pressure physicians for a prescription. J Fam Pract 2001;50: 853-8.

6. Bauchner H, Pelton SI, Klein JO. Parents, physicians, and antibiotic use. Pediatrics 1999;103:395-401.

7. Hamm RM, Hicks RJ, Bemben DA. Antibiotics and respiratory infections: are patients more satisfied when expectations are met? J Fam Pract 1996;43:56-62.

8. Merriam-Webster Online. http://www.m-w.com/ home.htm. Accessed June 30, 2005.
9. Gonzales R, Barrett PH Jr, Crane LA, Steiner JF. Factors associated with antibiotic use for acute bronchitis. J Gen Intern Med 1998;13:541-8.

10. Gonzales, R. What's in a name? Public knowledge, attitudes and experiences with antibiotic use for acute bronchitis. Am J Med 2000;108:83.

11. Collett CA, Pappas DE, Evans BA, Hayden GF. Parental knowledge about common respiratory infections and antibiotic therapy in children. South Med J 1999;92:971-6. 